\title{
Relationships between MGMT promoter methylation and gastric cancer: a meta-analysis
}

This article was published in the following Dove Press journal:

OncoTargets and Therapy

5 October 2016

Number of times this article has been viewed

\author{
Dan Yu \\ Tao Cao \\ Ya-Di Han \\ Fu-Sheng Huang \\ Department of Laboratory Medicine, \\ Center for Gene Diagnosis, Zhongnan \\ Hospital of Wuhan University, Wuhan, \\ People's Republic of China
}

\begin{abstract}
A DNA repair enzyme, O6-methylguanine-DNA methyltransferase ( $M G M T)$, plays an important role in the development of gastric cancers. However, the role of $M G M T$ promoter methylation in the occurrence of gastric cancer and its relationships with clinicopathologic characteristics has not been fully clarified. Thus, we performed a meta-analysis to evaluate the associations between $M G M T$ promoter methylation and gastric cancer. Electronic databases, including PubMed and Web of Science, were used to systematically search related clinical studies published in English until April 1, 2016. Odds ratios (ORs) and 95\% confidence intervals (95\% CIs) were calculated to evaluate the associations between MGMT promoter methylation and gastric cancer risk or clinicopathologic characteristics. A total of 16 studies including 1,935 patients and 1,948 control persons were included in the analysis. Our study suggested that $M G M T$ promoter methylation frequency was associated with gastric cancer $(\mathrm{OR}=3.46$, 95\% CI: 2.13-5.61, $P<0.001)$. Moreover, the frequency of $M G M T$ promoter methylation in the no lymph node metastasis group was lower than that in lymph node metastasis group, with marginal significance $(\mathrm{OR}=0.65,95 \% \mathrm{CI}$ : $0.42-1.01, P=0.05)$. Additionally, the methylation rate of the MGMT promoter was much lower in patients without distant metastases than in those with metastases $(\mathrm{OR}=0.27,95 \% \mathrm{CI}: 0.18-0.40, P<0.001)$. No significant association of $M G M T$ promoter methylation with Lauren classification, tumor location, tumor invasion, or Helicobacter pylori infection was found. In conclusion, the methylation status of the MGMT promoter was related to gastric cancer risk, distant metastasis, and lymph node metastasis, which indicates that $M G M T$ promoter methylation may play an important role in gastric cancer development.
\end{abstract}

Keywords: gastric cancer, tumor suppressor gene, cancer risks

\section{Introduction}

Gastric cancer is one of the most common cancers worldwide, with an estimated 951,600 new stomach cancer cases and 723,100 deaths in 2012. ${ }^{1}$ Although diagnostic methods, surgical techniques, and targeted therapy have improved, gastric cancer remains a notable clinical challenge. ${ }^{2}$ Many studies indicate that epigenetic alterations in tumor suppressor genes, such as cadherin $13,{ }^{3}$ Ras association domain family member $1,{ }^{4}$ methylation of O6-methylguanine-DNA methyltransferase (MGMT), ${ }^{5}$ and adenomatosis polyposis coli, ${ }^{6}$ play an important role in the initiation and progression of human cancer. DNA methylation is one of the most significant processes involved in epigenetic modifications and has an important effect on the development and prognosis of human cancer. ${ }^{7-10}$ In gastric cancer, hypermethylation of tumor suppressor genes has been frequently found. ${ }^{11}$

Among these tumor suppressor genes, $M G M T$ in gastric cancer has often been investigated. The MGMT gene, located at chromosome 10q26, includes one noncoding and four
Correspondence: Fu-Sheng Huang Department of Laboratory Medicine, Center for Gene Diagnosis, Zhongnan Hospital of Wuhan University, 169 Donghu Road, Wuchang, Wuhan, Hubei 43007I, People's Republic of China Tel +8627 678I 3233 Email huangfsuse@sina.com 
coding exons. ${ }^{12} M G M T$, a DNA repair enzyme, mainly defends cells against the carcinogenic effects of adducts by eliminating alkyl groups from the O6-position of guanine and then transferring them into its active center. ${ }^{13}$ O6-methylguanine (O6-mG) is the most potent mutagenic lesion that leads to a G-C to A-T transition mutation. MGMT can restore this mutagenesis of endogenous DNA damage and play an important role in maintaining normal cell physiology and genomic stability. ${ }^{14}$ Thus, loss of MGMT function can cause mutations, leading to human carcinogenesis. ${ }^{15} M G M T$ promoter methylation resulting in gene silencing and loss of function was found in many tumors, including colorectal cancer, ${ }^{16}$ non-small-cell lung cancer, ${ }^{17}$ gliomas, ${ }^{18}$ and gastric cancer. ${ }^{19}$ Oue et a ${ }^{20}$ first found that $M G M T$ promoter methylation may play a role in carcinogenesis in the stomach. Subsequently, many studies have demonstrated that MGMT methylation has been observed more frequently in gastric cancer tissues than in noncancer tissues, ${ }^{21-23}$ suggesting that MGMT methylation may be associated with an increased gastric cancer risk. However, contradictory results also existed. Therefore, we performed a meta-analysis to elucidate the associations between $M G M T$ promoter methylation and gastric cancer.

\section{Methods}

\section{Search strategy}

Electronic databases, including Web of Science, and PubMed, were used to systematically search related clinical studies published in English until April 1, 2016. The following terms were used: (methylation or DNA methylation or hypermethylation or demethylation), (gastric cancer or gastric carcinoma or gastric tumor), and (O-6-methylguanineDNA methyltransferase or $M G M T$ ).

\section{Inclusion and exclusion criteria}

Eligible studies met the following standards: 1) assessed the association between $M G M T$ methylation and gastric cancer; 2) case-control or cohort studies; 3) studies with sufficient data for calculating odds ratios (ORs) and their 95\% confidence intervals (CIs); 4) at least three case and control groups; 5) patients had a definite diagnosis of gastric cancer by pathological or histological examination. For duplicated data, only the most recent or comprehensive studies were included. Moreover, reviews, meta-analysis, case reports, letters, and animal and cell studies were excluded.

\section{Data extraction}

Data from the included studies were extracted independently by two authors. The following data were recorded from each study: First author's last name, year of publication, ethnicity, the frequency of $M G M T$ methylation in case and control groups, detection method, sample type, source of samples, the number of patients with distant metastasis status having a methylated and unmethylated status, lymph node status, sex, Lauren classification and Helicobacter pylori infection. Any differences of opinion were discussed till an agreement was reached.

\section{Statistical analysis}

Stata 12.0 (Stata Corporation, TX, USA) and Review Manager 5.2 (Cochrane Collaboration, Oxford, UK) were used in this meta-analysis. The ORs and 95\% CIs were used to evaluate the association between $M G M T$ promoter methylation and gastric cancer risk or clinicopathologic features. Heterogeneity between studies was evaluated by the Q-test based on the $\chi^{2}$ statistic and $I^{2}$ statistics. ${ }^{24}$ If substantial heterogeneity existed $\left(P<0.05\right.$ for the Q statistic or $\left.I^{2}>50 \%\right)$, a random effect model was applied to pool the ORs; otherwise, a fixed effect model was conducted. ${ }^{25}$ A meta-regression analysis was conducted to explore reasons for statistical heterogeneity. Additionally, subgroup analysis was performed based on sex, ethnicity, and sample size to determine the source of heterogeneity. A sensitivity analysis was conducted to assess the effect of single studies on the overall estimate by omitting one study at a time. A funnel plot, trim and fill method, and Egger's test were used to assess for publication bias. All tests were twosided, and $P<0.05$ denoted statistical significance.

\section{Results}

\section{Study selection and characteristics}

A total of 72 relevant articles were identified from electronic databases. After reading the titles, abstracts, and full text, 56 studies were excluded, because of irrelevant content, duplicated articles, non-English articles, inadequate data, and cell lines research. Finally, a total of 16 studies, ${ }^{21-23,26-38}$ consisting of 1,935 cases and 1,948 controls, were included in the analysis. The study selection process is shown in Figure 1. The methylation rate ranged from $6.9 \%$ to $70 \%$ in the cancer group and $0 \%$ to $44.9 \%$ in the control group. Among these studies, 4 studies were conducted on Caucasian, 11 studies on Asian, and 1 study on African individuals. Fourteen studies explored MGMT promoter methylation in tissues and two studies explored MGMT promoter methylation in blood. The basic characteristics of the included studies are shown in Table 1.

\section{Meta-analysis}

MGMT promoter methylation and gastric cancer risk Our results revealed that the frequency of $M G M T$ promoter methylation was increased in patients with gastric cancer 


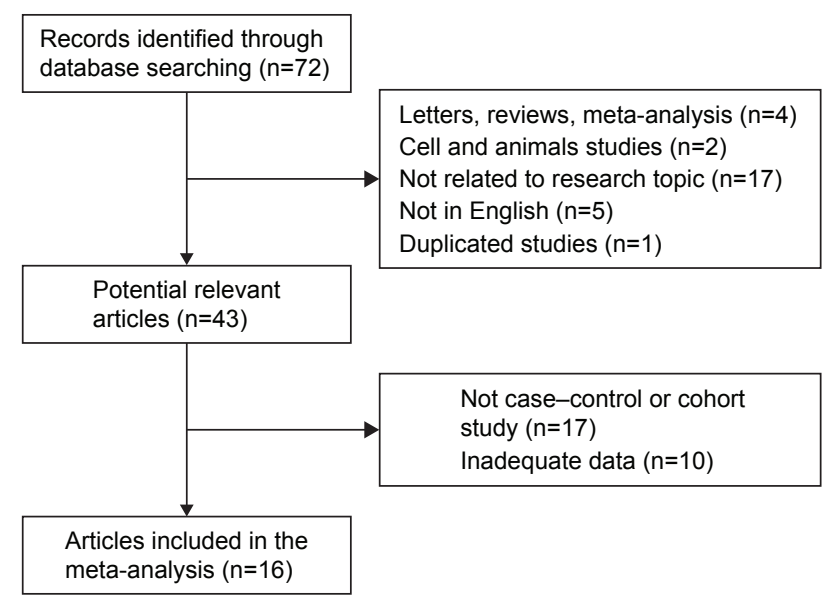

Figure I Flow chart of study selection.

compared with control groups under the random-effects model (OR=3.46, 95\% CI: 2.13-5.61, $P<0.001$, Figure 2). Because of marked heterogeneity $\left(P_{\mathrm{h}}<0.001, P^{2}=75 \%\right)$, a random effect model was performed. Subgroup analyses by ethnicity, sex, and case sample size were conducted to evaluate the potential source of heterogeneity. In the subgroup analysis based on ethnicity, the pool OR for MGMT promoter in the Caucasian subgroup was 2.70 (95\% CI: 0.61-12.06, $P=0.19)$ within a random effect model, and that for the Asians subgroup was 3.29 (95\% CI: 1.99-5.44, $P<0.001)$ under a random effect model. Subgroup analysis based on the case sample size indicated that in the $>60$ case group, the OR was 3.25 (95\% CI: $1.83-5.77, P<0.001)$ with a random effect model, in the $<60$ case group, the OR was 4.14 (95\% CI: $2.22-7.73, P<0.001)$ with a fixed effect model. Subgroup analysis by sex suggested no significant association between samples from female patients and those from male patients ( $\mathrm{OR}=0.75,95 \% \mathrm{CI}$ : $0.51-1.11, P=0.15$ ) based on a random effect model. Detailed results are summarized in Table 2.

Meta-regression analyses with the covariates of case sample size $(P=0.774)$ and ethnicity $(P=0.502)$ indicated no source of significant heterogeneity. Sensitivity analyses were conducted by excluding every study in turn to assess the stability of the overall results. The pooled OR with $95 \% \mathrm{CI}$ changed from $2.83(1.80,4.44)$ to $3.95(2.44,6.40)$ under a random effect model, indicating that pooled OR between $M G M T$ promoter methylation and gastric cancer was not a significant change. This also showed that our results were reliable and stable.

\section{MGMT promoter methylation and clinicopathologic}

\section{features in gastric cancer}

In terms of lymph node status in patients with gastric cancer, our results showed that the frequency of $M G M T$ promoter methylation in the no-lymph node metastasis group was lower than that in the lymph node metastasis group $(\mathrm{OR}=0.65$, 95\% CI: $0.42-1.01, P=0.05$, Figure 3) under a random effect model. Additionally, the rate of $M G M T$ promoter methylation was much lower in patients without distant metastases than in patients with metastases $(\mathrm{OR}=0.27$, $95 \%$ CI: $0.18-0.40, P<0.001$, Figure 4$)$ with a fixed effect model. Results revealed no significant association of $M G M T$ promoter methylation with Lauren classification $(\mathrm{OR}=0.95$, 95\% CI: $0.62-1.47, P=0.82$ ), tumor invasion ( $\mathrm{OR}=0.79$, 95\% CI: $0.60-1.04, P=0.09$ ), tumor location ( $\mathrm{OR}=0.90,95 \%$ CI: $0.68-1.20, P=0.049)$, or $H$. pylori infection $(\mathrm{OR}=1.02$, $95 \%$ CI: $0.54-1.93, P=0.94)$ with a fixed effect model. The detailed results are shown in Table 3.

\section{Publication bias}

The shapes of funnel plots, trim and fill method, and Egger's linear regression test were used to evaluate the publication bias. Slight asymmetry was observed in funnel plots, indicating that publication bias existed in evaluating the association of $M G M T$ promoter methylation with gastric cancer risk (Figure 5); however, the $P$-value of Egger's test was greater at 0.076 . Trim and fill analysis was performed, and the pooled OR was 2.05 (95\% CI: 1.26-3.33, $P<0.001)$. The results were similar to the crude meta-analysis, suggesting that our analyses were reliable.

\section{Discussion}

Gastric cancer is still a major clinical challenge with poor prognosis in recent years. A useful detection biomarker for the early diagnosis and prognosis evaluation is needed. Silencing tumor suppressor genes expression by aberrant methylation of the promoter regions has been found in the process of tumors..$^{39}$ Thus, by pooling the data from 16 studies, we investigated the associations of $M G M T$ promoter methylation with gastric cancer risk and its clinicopathologic features. According to our meta-analysis, MGMT promoter methylation was significantly correlated with the gastric cancer risk. Our results also suggested that the frequency of $M G M T$ promoter methylation was lower in the no-lymph node metastasis group than in the lymph node metastasis group, with marginal significance. More importantly, we found that distant metastasis was associated with increased $M G M T$ promoter hypermethylation.

The current meta-analysis revealed an association between $M G M T$ promoter methylation and gastric cancer risk. This was in line with previous studies in which the frequency of $M G M T$ promoter methylation in tumors was increased compared with control groups, ${ }^{23,27,28}$ although a 


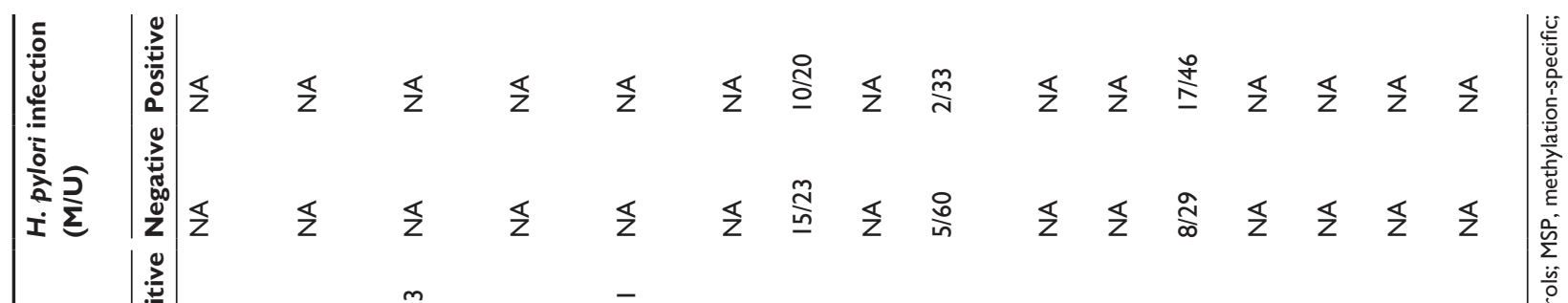

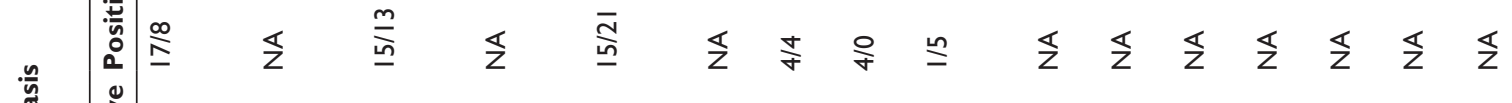

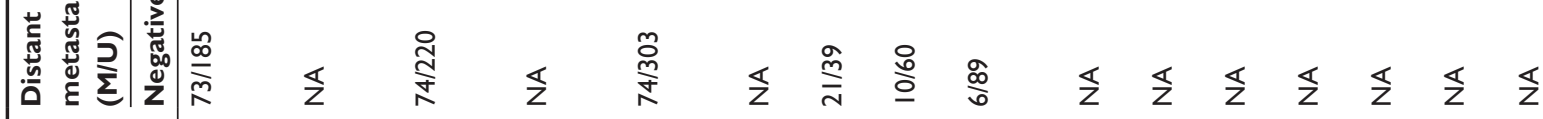

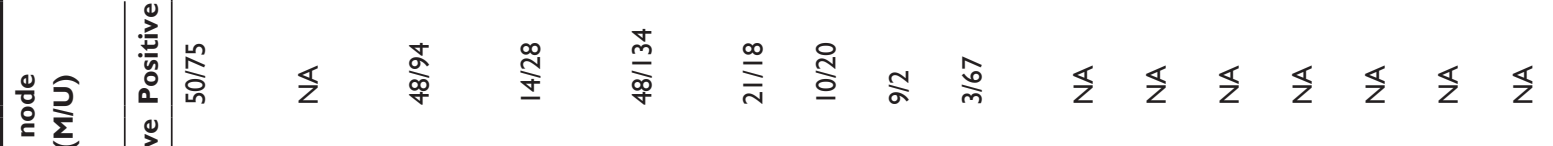

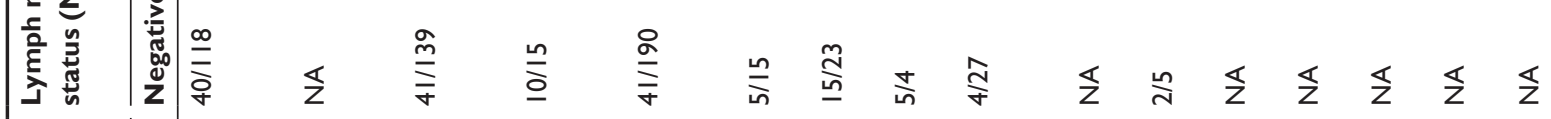

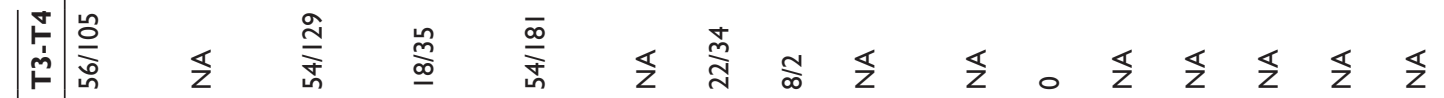

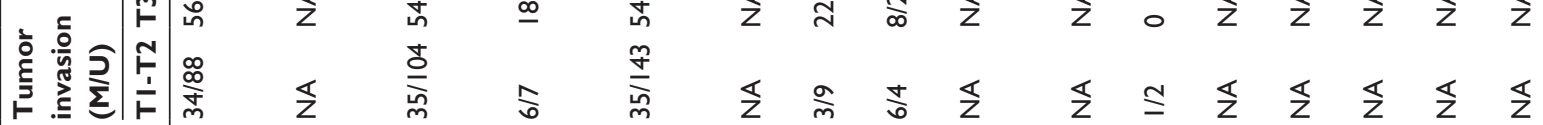

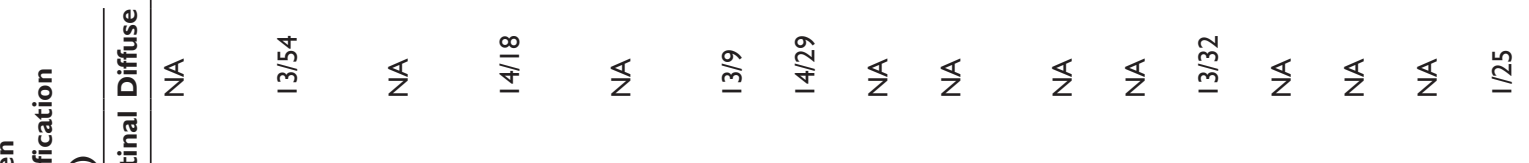

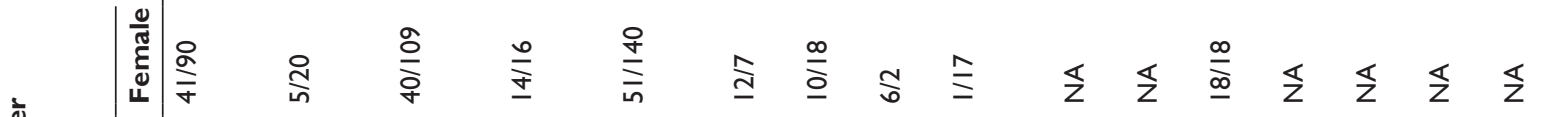

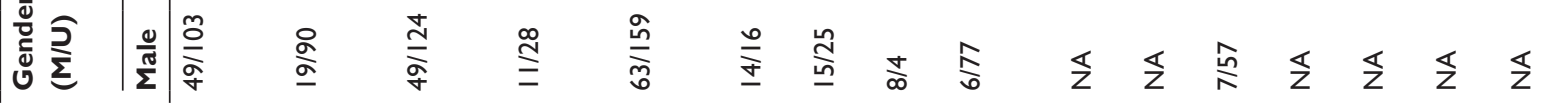

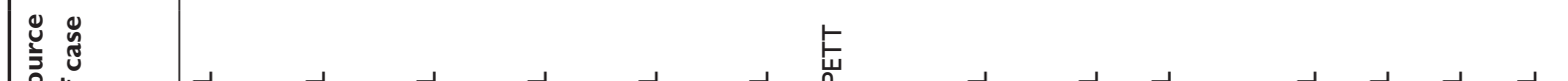
$\vec{\mho} \quad \vec{u}$ 安安安尗

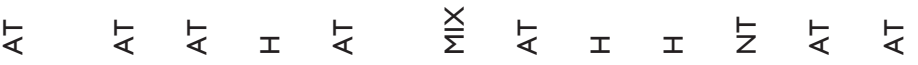

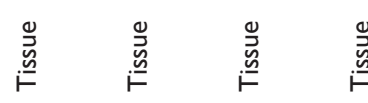
高

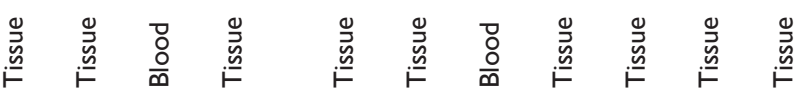

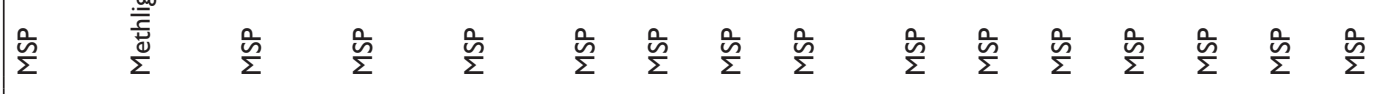

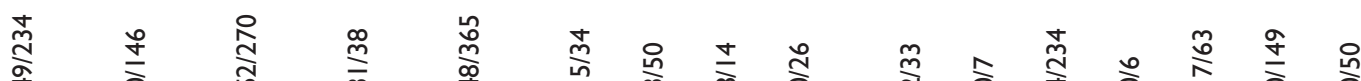

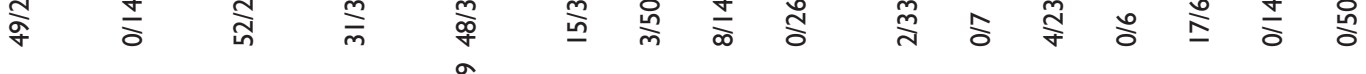

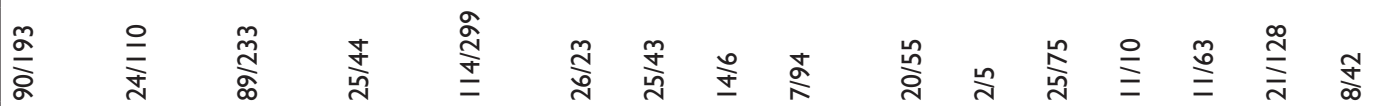

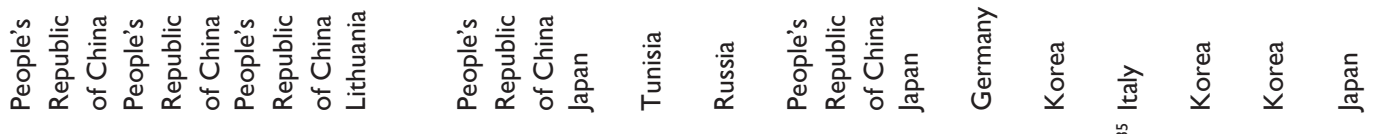

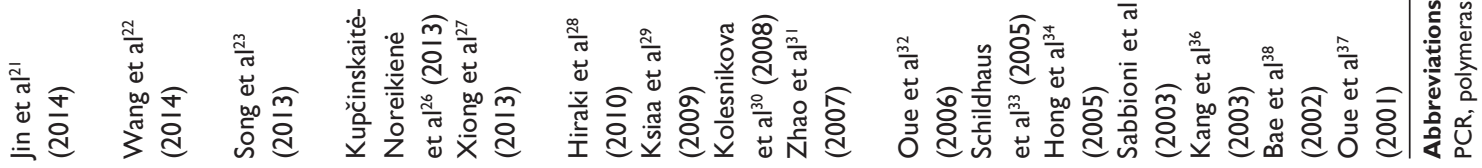




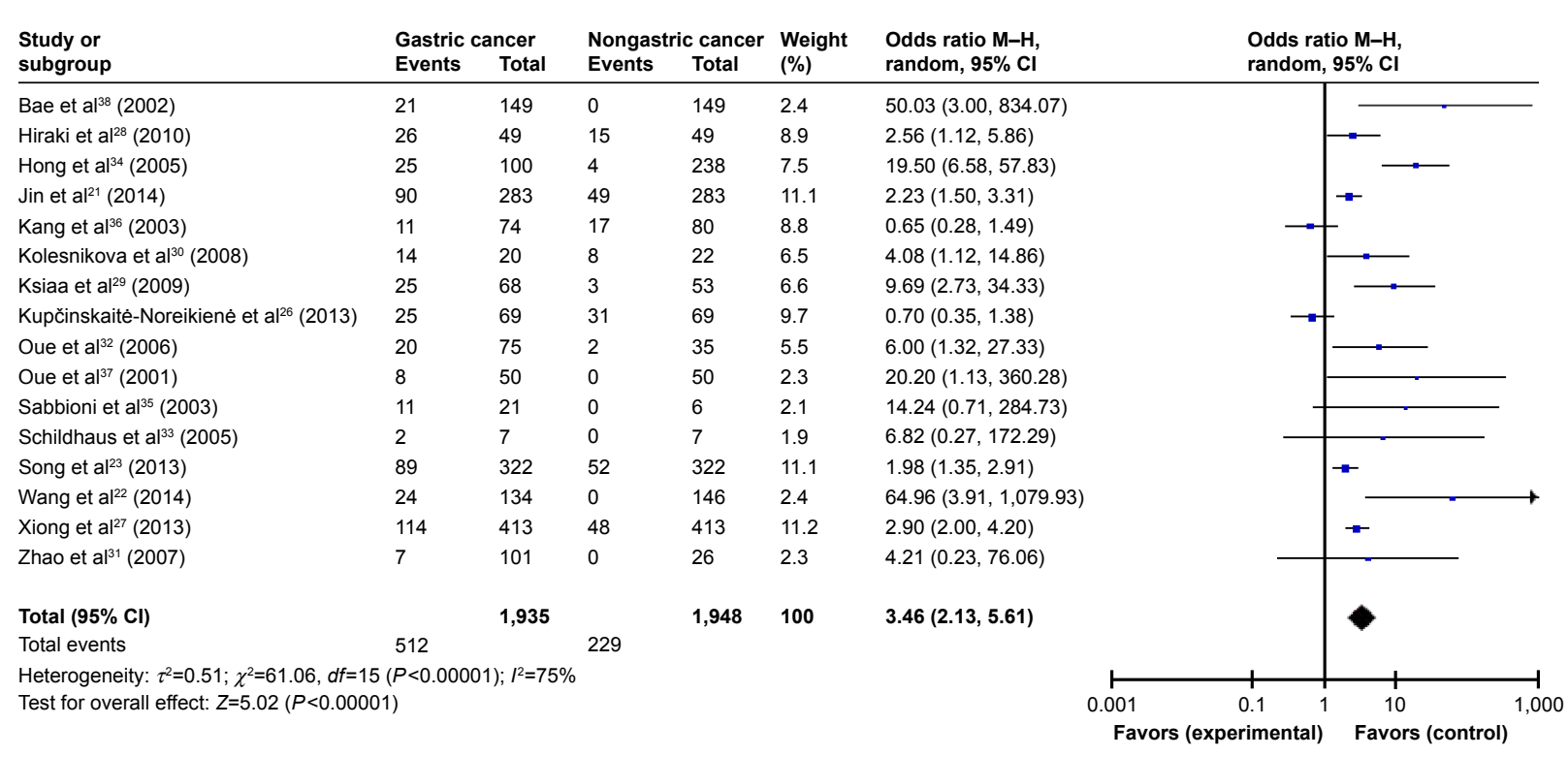

Figure 2 Forest plot for evaluating the association between MGMT promoter methylation and gastric cancer risk. Random-effect model was used for the analysis. Note: The pooled OR from 16 studies included I,935 gastric cancer and I,948 noncancer tissues (OR=3.46, 95\% Cl: 2.13-5.6I, $P<0.000 \mathrm{I})$.

Abbreviations: MGMT, O6-methylguanine-DNA methyltransferase; $\mathrm{Cl}$, confidence interval; $\mathrm{M}-\mathrm{H}$, Mantel-Haenszel; OR, odds ratio.

study by Kupčinskaitè-Noreikienè et $\mathrm{al}^{26}$ revealed no significant association between $M G M T$ promoter methylation and gastric cancer. $M G M T$ promoter methylation could be considered as a risk factor for the development of gastric cancer after large-scale studies are conducted. Silencing $M G M T$ expression by hypermethylation has two consequences for cancer. ${ }^{40}$ First, $M G M T$ can defend cell against alkylation-induced gene mutations, toxicity, and carcinogenicity. ${ }^{41}$ Alkylating agent can result in alkylation of $\mathrm{O} 6$ guanine in DNA. O6-methylguanine preferentially pairs with thymine in DNA replication leading to a G-C to A-T transition mutation ${ }^{42}$ and can lead to cross-linking reactions with cytosine on the side chain, resulting in termination of DNA synthesis. These changes may result in K-ras mutation or p53 mutation ${ }^{38}$ leading to the development of cancer.

Table 2 Stratified analysis of the frequency of MGMT promoter methylation in gastric cancers compared with noncancer controls

\begin{tabular}{|c|c|c|c|c|c|c|}
\hline Study group & $\mathbf{N}$ & OR (95\% Cl) & $I^{2}(\%)$ & $P_{h}$ & $\boldsymbol{P}_{\text {bias }}$ & $P$-value \\
\hline Total & 16 & $3.46(2.13,5.6 \mathrm{I})$ & 75 & $<0.001$ & 0.076 & $<0.001$ \\
\hline \multicolumn{7}{|l|}{ Ethnicity } \\
\hline Caucasian & 4 & $2.70(0.61,12.06)$ & 69 & 0.02 & 0.126 & 0.19 \\
\hline Asians & 11 & $3.29 i$ & 73 & $<0.001$ & 0.063 & $<0.001$ \\
\hline Africans & I & $9.69(2.73,34.33)$ & NA & NA & NA & $<0.001$ \\
\hline \multicolumn{7}{|l|}{ Case sample } \\
\hline \multicolumn{7}{|l|}{ size } \\
\hline$<60$ & 5 & $4.14(2.22,7.73)$ & 0 & 0.52 & 0.021 & $<0.001$ \\
\hline$>60$ & 11 & $3.25(1.83,5.77)$ & 82 & $<0.001$ & 0.120 & $<0.001$ \\
\hline
\end{tabular}

Note: Values in bold indicate statistical significance.

Abbreviations: $\mathrm{Cl}$, confidence interval; MGMT, O6-methylguanine-DNA methyltransferase; $N$, total number of eligible studies; NA, not available; OR, odds ratio; $P_{\text {bias }}, P$-value of Egger linear regression test for evaluating publication bias; $P_{\mathrm{h}}, P$-value of $Q$ test for heterogeneity among studies.
Unrepaired DNA damage is a major source of potentially mutagenic lesions that may lead to cancer. ${ }^{43}$ Second, $M G M T$ hypermethylation in tumors is sensitive to alkylating drugs used in chemotherapy. MGMT promoter methylation has been associated with chemo-responsiveness with alkylating agent drugs in glioma, Hodgkin's lymphoma cells and other tumor models. ${ }^{44,45}$ Silencing MGMT gene expression by promoter methylation can increase the sensitivity to temozolomide, which is considered a therapeutic option for some gastric cancers. Additionally, Miura et al indicated that negative expression of the MGMT gene was observed in $45 \%$ of the gastroesophageal tumors on the basis of biomarker profiling, suggesting potential sensitivity to temozolomide. ${ }^{46}$ Therefore, it is necessary to detect the MGMT promoter methylation status in patients with gastric cancer to develop individualized treatment programs when they are treated with temozolomide.

In the subgroup analysis based on ethnicity, a significant association between $M G M T$ promoter methylation and gastric cancer risk was observed in Asians, but no significant difference was found in Caucasians. It suggested that a combination of differences in gene backgrounds and the environment may have certain impact on the prevalence of MGMT methylation. Furthermore, limited studies were conducted on Caucasians, which may bring about a falsenegative result. Further study is warranted to investigate the association between $M G M T$ promoter methylation and gastric cancer in Caucasians. In the subgroup analysis of sample size, statistical associations were found for all 


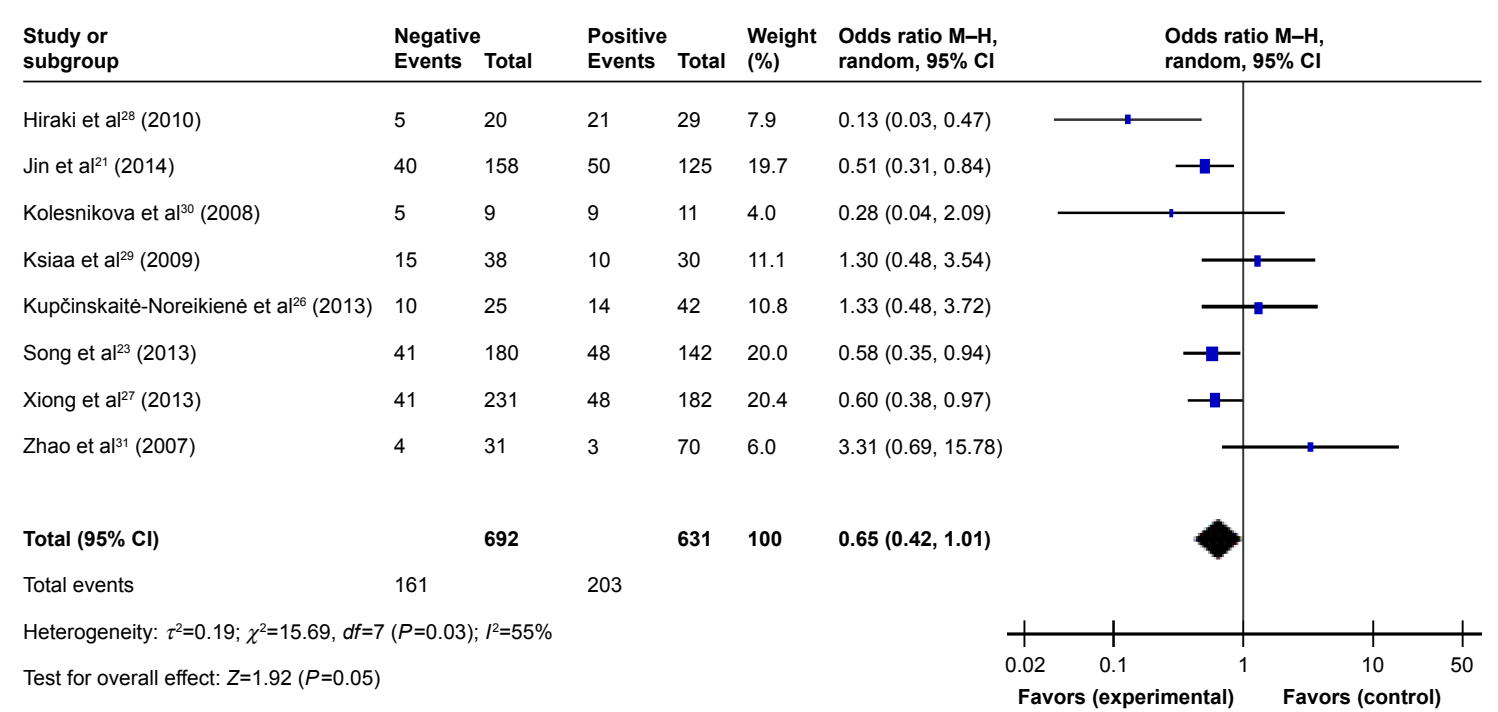

Figure 3 Forest plot for evaluating the association between MGMT promoter methylation and lymph node metastasis. Random-effect model was used for the analysis. Notes: The pooled OR from 9 studies included 692 gastric cancer patients with no lymph node metastasis and 638 patients with lymph node metastasis (OR=0.65, $95 \%$ Cl: 2.13-0.42, $P=0.05)$. Negative: patients with no lymph node metastasis, positive: patients with lymph node metastasis.

Abbreviations: MGMT, O6-methylguanine-DNA methyltransferase; $\mathrm{Cl}$, confidence interval; $\mathrm{M}-\mathrm{H}$, Mantel-Haenszel; OR, odds ratio.

subgroups. Additionally, the results of subgroup analysis based on sex revealed that $M G M T$ promoter methylation has no relationship with sex in patients with gastric cancer patients.

The associations between $M G M T$ promoter methylation and Lauren classification, H. pylori infection, tumor location, distant metastasis, and lymph node status were also investigated. Our results showed that MGMT promoter methylation was related to lymph node metastasis and distant metastasis was observed in our study, indicating that MGMT promoter methylation may be involved in the metastasis of gastric cancer. The tumor microenvironment plays an important role in tumor progression and may exert an influence on the epigenetic status of micrometastatic colonies in the lymph nodes. ${ }^{47}$ Therefore, the frequency of methylation differs depending on whether lymph node metastasis has occurred. Therefore, it was hypothesized that MGMT promoter methylation may serve as a biomarker for monitoring gastric cancer metastasis. Furthermore, $\mathrm{Li}$ et $\mathrm{a}^{48}$ investigated the role of $M G M T$ in gastric cancer cell migration, invasion, and metastatic potential. They demonstrated that loss of $M G M T$ expression induced increases in gastric cancer cell metastasis

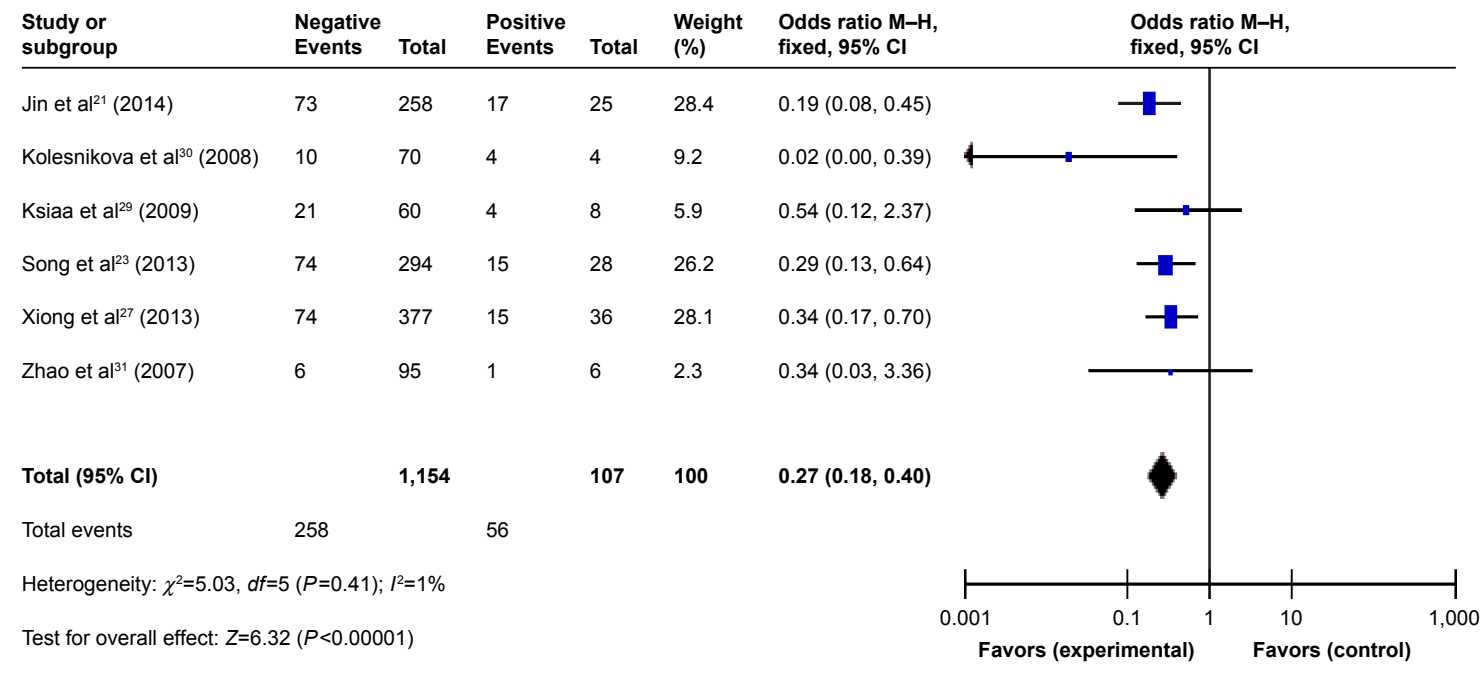

Figure 4 Forest plot for evaluating the association between MGMT promoter methylation and distant metastasis. Fixed-effect model was used for the analysis. Notes: The pooled OR from 6 studies included I, I 54 gastric cancer patients with no distant metastasis and I07 patients with distant metastasis (OR=0.27, 95\% Cl: $0.18-0.40$, $P<0.000$ I). Negative: patients with no distant metastasis, positive: patients with distant metastasis.

Abbreviations: MGMT, O6-methylguanine-DNA methyltransferase; $\mathrm{Cl}$, confidence interval; $\mathrm{M}-\mathrm{H}$, Mantel-Haenszel; OR, odds ratio. 
Table 3 Association of MGMT promoter methylation with clinicopathologic features in gastric cancer

\begin{tabular}{|c|c|c|c|c|c|c|}
\hline $\begin{array}{l}\text { Clinicopathologi } \\
\text { characteristics }\end{array}$ & & & $\begin{array}{l}I^{2} \\
\text { (\%) }\end{array}$ & $P_{h}$ & $\boldsymbol{P}_{\text {bias }}$ & $P$-value \\
\hline Gender & & $0.75(0.5 \mathrm{I}, \mathrm{I} . \mathrm{II})$ & 52 & $P=0.03$ & & \\
\hline Lauren classification & 6 & 0.95 & 38 & $P=0.15$ & $P=0.079$ & \\
\hline Tumor invasion & 7 & $0.79(0.60,1.04)$ & 0 & $P=0.86$ & $P=0.945$ & 50.09 \\
\hline tastasis & 6 & $0.27(0.18,0.40)$ & 1 & $P=0.41$ & $P=0.435$ & $5<0.001$ \\
\hline Lymph node status & 9 & $0.65(0.42,1.01)$ & 55 & $P=0.03$ & $P=0.674$ & 40.05 \\
\hline H. pylori infection & 3 & $1.02(0.54,1.93)$ & 0 & $P=0.68$ & $P=0.881$ & 0.94 \\
\hline Tumor location & 3 & $0.9(0.68,1.20)$ & 0 & $P=0.80$ & $P=0.470$ & 00.49 \\
\hline
\end{tabular}

Note: Values in bold indicate statistical significance.

Abbreviations: $H$. pylori, Helicobacter pylori; MGMT, O6-methylguanine-DNA methyltransferase; $\mathrm{N}$, total number of eligible studies; $P_{\text {bias }}, P$-value of Egger linear regression test for evaluating publication bias; $P_{\mathrm{h}}, P$-value of $\mathrm{Q}$ test for heterogeneity among studies.

by downregulation of matrix metalloproteinase 2. However, no obvious association of $M G M T$ promoter methylation and Lauren classification was found in our meta-analysis, suggesting that $M G M T$ promoter methylation had no effect on the different pathological types of gastric cancer. Additionally, no significant association was identified between $M G M T$ promoter methylation and tumor invasion. Multiple high-quality studies are needed to further investigate these associations. Recent studies have indicated that viral or bacterial infections were related to aberrant DNA methylation. ${ }^{49}$ The increased DNA methylation levels of some tumor-suppressor genes, such as p16 (INK4a), angiopoietin like 4s (ANGPTL4), $M G M T$, and four and a half LIM domains 1 (FHL1) owing to $H$. pylori infection were observed in the gastric mucosa. ${ }^{50}$ However, no significant correlation was found between MGMT promoter methylation and $H$. pylori infection in our meta-analysis, which included three studies. This clear mechanism needs further study. Kupcinskaite-Noreikiene et $\mathrm{al}^{51}$ suggested that the rate of methylation of the MGMT

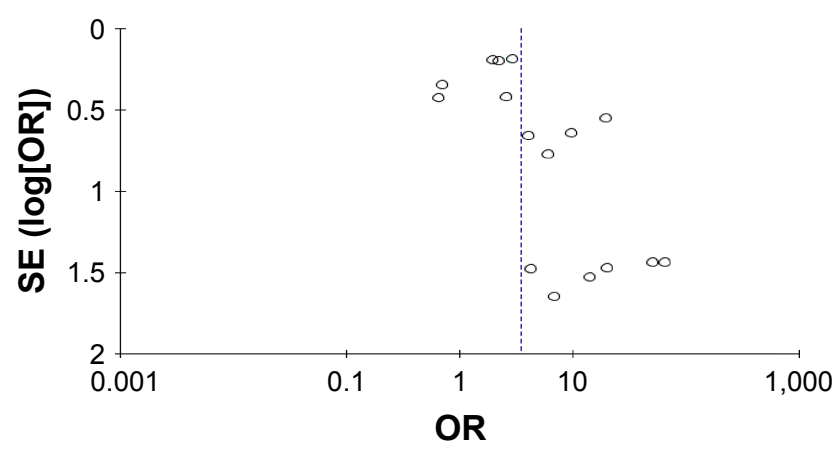

Figure 5 Funnel plot for evaluating the association of MGMT promoter methylation with gastric cancer risk.

Note: The funnel plot from 16 studies determined the relationship between MGMT hypermethylation and gastric cancer.

Abbreviations: MGMT, O6-methylguanine-DNA methyltransferase; OR, odds ratio; SE, standard error. promoter was higher in the lower third of the stomach than in the upper third, so we divided our studies into two groups according to the primary tumor location. Stratification by tumor location revealed that no associations between $M G M T$ promoter methylation and tumor location $(\mathrm{OR}=0.90,95 \% \mathrm{CI}$ : $0.68-1.20, P=0.49)$ within a fixed effect model, because the number of patients in the meta-analysis was relatively small. Further studies are needed to clarify this.

Several potential limitations were noted in this metaanalysis. First, significant heterogeneity between studies existed, but no sources of heterogeneity were found by meta-regression and subgroup analysis. The control group consisted of both normal gastric tissue adjacent to the tumor and normal gastric tissue, thus, the diversity of control groups may have effected on our research results. Thus, the nonuniform definition of control groups may lead to some heterogeneity. Second, many other factors, such as age as a risk factor for gastric cancer, $M G M T$ mRNA expression, tumor grade, 10-year disease-free survival, disease-specific survival, and general demographic information, could not be assessed because of inadequate data. Large detailed studies should be included in further research. Third, we chose the only studies published in English, and this may contribute to potential selection bias, which may not be possible to avoid entirely. Finally, all included studies were retrospective; hence, it is impossible to determine whether $M G M T$ promoter methylation is an early cancer-causing aberration or an influence of cancer progression. In the future, multiple prospective studies should be conducted to clarify this.

Although this study does have some limitations, it also has some strengths. Most importantly, our study showed a strong association of $M G M T$ promoter methylation with risk of gastric cancer, which is consistent with previous findings that $M G M T$ promoter methylation could be a risk factor for other types of cancer, such as colon adenocarcinoma, ${ }^{52}$ breast cancer, ${ }^{4}$ and non-small-cell lung cancer. ${ }^{53}$ Moreover, we found that $M G M T$ promoter methylation may serve as a biomarker for monitoring gastric cancer metastasis, although many future studies are recommended to repeat these findings. $M G M T$ promoter methylation has been associated with chemo-responsiveness with alkylating agent drugs; therefore, it is essential to detect the $M G M T$ promoter methylation status in patients if they need treatment with alkylating agent drugs.

In summary, MGMT promoter hypermethylation is associated with gastric risk, distant metastasis and lymph node metastasis, which indicates that MGMT promoter methylation may play an important role in gastric cancer. However, 
large-scale multicenter and well-matched cohort research studies are warranted to confirm our results and elucidate the exact mechanisms involved.

\section{Acknowledgment}

This work was supported by the National Natural Science Foundation of China (81171669).

\section{Disclosure}

The authors report no conflicts of interest in this work.

\section{References}

1. Torre LA, Bray F, Siegel RL, Ferlay J, Lortet-Tieulent J, Jemal A. Global cancer statistics, 2012. CA: Cancer J Clin. 2015;65(2):87-108.

2. Yang W, Raufi A, Klempner SJ. Targeted therapy for gastric cancer: molecular pathways and ongoing investigations. Biochim Biophys Acta. 2014;1846(1):232-237.

3. Chmelarova M, Sirak I, Mzik M, et al. Importance of Tumour Suppressor Gene Methylation in Sinonasal Carcinomas. Folia Biol(Praha). 2016;62(3):110-119.

4. Spitzwieser M, Holzweber E, Pfeiler G, Hacker S, Cichna-Markl M. Applicability of HIN-1, MGMT and RASSF1A promoter methylation as biomarkers for detecting field cancerization in breast cancer. Breast Cancer Res. 2015;17:125.

5. Martinelli CM, Lengert AV, Carcano FM, et al. MGMT and CALCA promoter methylation are associated with poor prognosis in testicular germ cell tumor patients. Oncotarget. Epub 2016 Aug 10.

6. He K, Zhang L, Long X. Quantitative assessment of the association between APC promoter methylation and breast cancer. Oncotarget. Epub 2016 May 13.

7. Tie J, Zhang X, Fan D. Epigenetic roles in the malignant transformation of gastric mucosal cells. Cell Mol Life Sci. Epub 2016 Jul 27.

8. Klutstein M, Nejman D, Greenfield R, Cedar H. DNA Methylation in cancer and aging. Cancer Res. 2016;76(12):3446-3450.

9. Zheng SC, Widschwendter M, Teschendorff AE. Epigenetic drift, epigenetic clocks and cancer risk. Epigenomics. 2016;8(5): 705-719.

10. Kim YJ, Kim WJ. Can we use methylation markers as diagnostic and prognostic indicators for bladder cancer? Investig Clin Urol. 2016; 57(Suppl 1):S77-S88.

11. Oh JH, Jung SH, Hong SJ, Rhyu MG. DNA Methylation as Surrogate Marker For Gastric Cancer. J Cancer Prev. 2015;20(3):172-178.

12. Christmann M, Tomicic MT, Roos WP, Kaina B. Mechanisms of human DNA repair: an update. Toxicology. 2003;193(1-2):3-34.

13. Ishikawa T, Zhang SS, Qin X, et al. DNA repair and cancer: lessons from mutant mouse models. Cancer Sci. 2004;95(2):112-117.

14. Gerson SL. MGMT: its role in cancer aetiology and cancer therapeutics. Nature reviews Cancer. Apr 2004;4(4):296-307.

15. Soejima H, Zhao W, Mukai T. Epigenetic silencing of the MGMT gene in cancer. Biochem Cell Biol. 2005;83(4):429-437.

16. Fornaro L, Vivaldi C, Caparello C, et al. Pharmacoepigenetics in gastrointestinal tumors: MGMT methylation and beyond. Front Biosci. 2016;8:170-180.

17. Gu C, Lu J, Cui T, et al. Association between MGMT promoter methylation and non-small cell lung cancer: a meta-analysis. PloS One. 2013;8(9):e72633.

18. Mur P, Rodriguez de Lope A, Diaz-Crespo FJ, et al. Impact on prognosis of the regional distribution of MGMT methylation with respect to the $\mathrm{CpG}$ island methylator phenotype and age in glioma patients. J Neurooncology. 2015;122(3):441-450.

19. Yousuf A, Bhat MY, Pandith AA, et al. MGMT gene silencing by promoter hypermethylation in gastric cancer in a high incidence area. Cell Oncol (Dordr). 2014;37(4):245-252.
20. Oue N, Shigeishi H, Kuniyasu H, et al. Promoter hypermethylation of MGMT is associated with protein loss in gastric carcinoma. Int J Cancer. 2001;93(6):805-809.

21. Jin J, Xie L, Xie CH, Zhou YF. Aberrant DNA methylation of MGMT and hMLH1 genes in prediction of gastric cancer. Genet Mol Res. 2014; 13(2):4140-4145.

22. Wang M, Li Y, Gao J, et al. p16 Methylation is associated with chemosensitivity to fluorouracil in patients with advanced gastric cancer. Med Oncol. 2014;31(6):988.

23. Song B, Ai J, Kong X, Liu D, Li J. Aberrant DNA Methylation of P16, MGMT, and hMLH1 Genes in Combination with MTHFR C677T Genetic Polymorphism in gastric cancer. PakJ Med Sci. 2013; 29(6):1338-1343.

24. Higgins JP, Thompson SG, Deeks JJ, Altman DG. Measuring inconsistency in meta-analyses. BMJ. 2003;327(7414):557-560.

25. Zintzaras E, Ioannidis JP. Heterogeneity testing in meta-analysis of genome searches. Genet Epidemiol. 2005;28(2):123-137.

26. Kupčinskaitè-Noreikienė R, Skieceviciene J, Jonaitis L, et al. CpG island methylation of the MLH1, MGMT, DAPK, and CASP8 genes in cancerous and adjacent noncancerous stomach tissues. Medicina (Kaunas). 2013;49(8):361-366.

27. Xiong HL, Liu XQ, Sun AH, He Y, Li J, Xia Y. Aberrant DNA methylation of P16, MGMT, hMLH1 and hMSH2 genes in combination with the MTHFR C677T genetic polymorphism in gastric cancer. Asian Pac J Cancer Prev. 2013;14(5):3139-3142.

28. Hiraki M, Kitajima Y, Sato S, et al. Aberrant gene methylation in the lymph nodes provides a possible marker for diagnosing micrometastasis in gastric cancer. Ann Surg Oncol. 2010;17(4):1177-1186.

29. Ksiaa F, Ziadi S, Amara K, Korbi S, Trimeche M. Biological significance of promoter hypermethylation of tumor-related genes in patients with gastric carcinoma. Clin Chim Acta. 2009;404(2):128-133.

30. Kolesnikova EV, Tamkovich SN, Bryzgunova OE, et al. Circulating DNA in the blood of gastric cancer patients. Ann N Y Acad Sci. 2008; 1137:226-231.

31. Zhao YF, Zhang YG, Tian XX, Juan D, Jie Z. Aberrant methylation of multiple genes in gastric carcinomas. Int J Surg Pathol. 2007;15(3): 242-251.

32. Oue N, Mitani Y, Motoshita J, et al. Accumulation of DNA methylation is associated with tumor stage in gastric cancer. Cancer. 2006; 106(6): 1250-1259.

33. Schildhaus HU, Krockel I, Lippert H, Malfertheiner P, Roessner A, Schneider-Stock R. Promoter hypermethylation of p16INK4a, E-cadherin, O6-MGMT, DAPK and FHIT in adenocarcinomas of the esophagus, esophagogastric junction and proximal stomach. Int J Oncol. 2005; 26(6): 1493-1500.

34. Hong SH, Kim HG, Chung WB, et al. DNA hypermethylation of tumor-related genes in gastric carcinoma. J Korean Med Sci. 2005;20(2):236-241.

35. Sabbioni S, Miotto E, Veronese A, et al. Multigene methylation analysis of gastrointestinal tumors: TPEF emerges as a frequent tumor-specific aberrantly methylated marker that can be detected in peripheral blood. Mol Diagn. 2003;7(3-4):201-207.

36. Kang GH, Lee S, Kim JS, Jung HY. Profile of aberrant CpG island methylation along the multistep pathway of gastric carcinogenesis. Lab Invest. 2003;83(5):635-641.

37. Oue N, Sentani K, Yokozaki H, Kitadai Y, Ito R, Yasui W. Promoter methylation status of the DNA repair genes hMLH1 and MGMT in gastric carcinoma and metaplastic mucosa. Pathobiology. 2001; 69(3):143-149.

38. Bae SI, Lee HS, Kim SH, Kim WH. Inactivation of O6-methylguanineDNA methyltransferase by promoter $\mathrm{CpG}$ island hypermethylation in gastric cancers. Br J cancer. 2002;86(12):1888-1892.

39. Herman JG, Baylin SB. Gene silencing in cancer in association with promoter hypermethylation. N Engl J Med. 2003;349(21):2042-2054.

40. Esteller M, Herman JG. Generating mutations but providing chemosensitivity: the role of O6-methylguanine DNA methyltransferase in human cancer. Oncogene. 2004;23(1):1-8. 
41. Scesnaite A, Jarmalaite S, Mueller M, et al. Prognostic value of O-6-methylguanine-DNA methyltransferase loss in salivary gland carcinomas. Head Neck. 2014;36(9):1258-1267.

42. Park TJ, Han SU, Cho YK, Paik WK, Kim YB, Lim IK. Methylation of $\mathrm{O}(6)$-methylguanine-DNA methyltransferase gene is associated significantly with K-ras mutation, lymph node invasion, tumor staging, and disease free survival in patients with gastric carcinoma. Cancer. 2001;92(11):2760-2768.

43. Abbotts R, Thompson N, Madhusudan S. DNA repair in cancer: emerging targets for personalized therapy. Cancer Manag Res. 2014; 6:77-92.

44. Hegi ME, Diserens AC, Gorlia T, et al. MGMT gene silencing and benefit from temozolomide in glioblastoma. $N$ Engl J Med. 2005; 352(10):997-1003.

45. Kewitz S, Stiefel M, Kramm CM, Staege MS. Impact of O6-methylguanine-DNA methyltransferase (MGMT) promoter methylation and MGMT expression on dacarbazine resistance of Hodgkin's lymphoma cells. Leuk Res. 2014;38(1):138-143.

46. Miura JT, Xiu J, Thomas J, et al. Tumor profiling of gastric and esophageal carcinoma reveal different treatment options. Cancer Biol Ther. 2015;16(5):764-769.
47. Huynh KT, Hoon DS. Epigenetics of regional lymph node metastasis in solid tumors. Clin Exp Metastasis. 2012;29(7):747-756.

48. Li C, Deng L, Shen Q, et al. O-6-methylguanine-DNA Methyltransferase Inhibits Gastric Carcinoma Cell Migration and Invasion by Downregulation of Matrix Metalloproteinase 2. Anticancer Agents Med Chem. 2016;16(9):1125-1132.

49. Hattori N, Ushijima T. Epigenetic impact of infection on carcinogenesis: mechanisms and applications. Genome Med. 2016;8(1):10.

50. Shiotani A, Cen P, Graham DY. Eradication of gastric cancer is now both possible and practical. Semin Cancer Biol. 2013;23(6 Pt B):492-501.

51. Kupcinskaite-Noreikiene R, Ugenskiene R, Noreika A, et al. Gene methylation profile of gastric cancerous tissue according to tumor site in the stomach. BMC cancer. 2016;16:40.

52. Michailidi C, Theocharis S, Tsourouflis G, et al. Expression and promoter methylation status of hMLH1, MGMT, APC, and CDH1 genes in patients with colon adenocarcinoma. Exp Biol Med (Maywood). 2015;240(12):1599-1605.

53. Fang N, Gu J, Wei H, You J, Zhou Q. [A meta-analysis of Association between MGMT gene promoter methylation and non-small cell lung cancer]. Zhongguo fei ai za zhi. 2014;17(8):601-605.

\section{Publish your work in this journal}

OncoTargets and Therapy is an international, peer-reviewed, open access journal focusing on the pathological basis of all cancers, potential targets for therapy and treatment protocols employed to improve the management of cancer patients. The journal also focuses on the impact of management programs and new therapeutic agents and protocols on

\section{Dovepress}

patient perspectives such as quality of life, adherence and satisfaction. The manuscript management system is completely online and includes a very quick and fair peer-review system, which is all easy to use. Visit http://www.dovepress.com/testimonials.php to read real quotes from published authors. 